\title{
TREATMENT OF SPILLED CRUDE OIL IN ENVIRONMENT USING ENVIRONMENTALLY FRIENDLY NONIONIC TWEEN SURFACTANTS
}

\author{
Naglaa K. Ibrahim ${ }^{(1)}$; Mohamed Y. Elkady ${ }^{(2)}$;
} Mohamed F. EIMenier ${ }^{(1)}$ and Nabel A. Negm ${ }^{(3)}$

1) Misr Petroleum Company, Cairo, Egypt 2) Faculty of Science, Ain Shams University 3) Petrochemicals Department, Egyptian Petroleum Research Institute, Nasr city, Cairo, Egypt.

\begin{abstract}
Crude oil spills in the environment; either in soil or in water of rivers and seas is considered a great environmental problem. That is due to the presence of crude oil in the open water has a negative impact on the ecosystem of fishes and their respiration. Furthermore, crude oil has poisoning components which harm the ecological system. The effective method of treating the spilled crude oil in the environment is the formation of dispersions for this oil, which prevents the accumulation of the crude oil in specific area and allows its biodegradation by the microorganisms. Here, environmentally friendly nonionic surfactants, namely: Tween-20,40,60 and 80 were investigated as dispersants for dispersing the crude oil spilled in the ecosystem. The study showed that the polyethylene glycol chain length of the different tweens has a great influence on their ability to form crude oil emulsions. Furthermore, the surface activity of the investigated surfactants was an important factor in their crude oil dispersing function.
\end{abstract}

Keywords: crude oil, environmental pollution, ecosystem, nonionic surfactants.

\section{INTRODUCTION}

Crude oil is a complex liquid mixture made up of a vast number of hydrocarbon compounds that consist mainly of carbon and hydrogen in 
differing proportions. In addition, small amounts of organic compounds containing sulfur, oxygen, nitrogen and metals such as vanadium, nickel, iron and copper exist in the crude. There are three main classes of hydrocarbons saturated hydrocarbons paraffins (or alkanes), naphthenes (or cycloalkanes),unsaturated hydrocarbons olefins, aromatic hydrocarbons beside heterocyclic compunds e.g.: pyridines, thiophenes, and polycondensed compounds. The components of the crude oil are highly toxic to the human, animals, plants and aquatic system. Crude oil can be spilled in the environment during the exploration, transportation, storage and refining.

Marine ecosystems are structured in complex ways by many interacting species, and an oil spill will have a different impact on each of them(Stephanie et al., 2014). The chemical composition and quantity of the oil to which organisms are exposed are important factors determining how populations will respond to spilled oil. Marine mammals and bird species, which must regularly pass through the air-water interface to breathe, are particularly vulnerable to oil exposure (Peterson et al.,2003), whereas pelagic fish species will have minimal exposure to oil (Paine et al.,1996). In spill disasters in which the oil floats, the greatest exposure will occur in the intertidal zone, where rising and falling tides bring species in direct contact with the bulk of the spilled oil.Toxicity pathways in different species are myriad and some examples may include ingestion of oil, accumulation of contaminants in tissues, DNA damage, impacts to immune functioning, cardiac dysfunction, mass mortality of eggs and larvae, e.g., in fish, loss of buoyancy and insulation for birds, and inhalation of vapors (Judson et al.,2010؛Major and Wang, 2012). 
Chemical dispersants can be applied to the oil to break down the oil into small droplets.Oil can be combusted via scorching; mechanically removed; washed off the shoreline using high pressure hot water hoses; can be skimmed off the surface or absorbed. All of these procedures further damage marine ecosystems and, perhaps counter-intuitively, increase the amount of time required for ecosystems to recover from the oil spill (Foster et al., 1990). The chemical dispersants used to break down oil are toxic (Sriram et al., 2011), and the combination of oil and dispersant can have stronger negative effects on marine species than the oil alone (Vosyliene et al., 2005). Although some algae may possess protective mechanisms against the toxic effects of dispersants (Wolfe et al., 1999), protective mechanisms in mammals are as yet poorly understood. The bioavailability of oil increases after dispersal, which can directly expose organisms to increased levels of hydrocarbons and allow the hydrocarbon-dispersant formed to enter the food chain (Mascarelli, 2010).

\section{MATERIALS AND METHODS}

\section{Materials:}

In this work, the used nonionic surfactants: Tween-20, Tween-40, Tween-60 and Tween-80 were purchased from Sigma-Aldrich. The chemical names of these surfactants are polyoxyethylene sorbitans and their formule are: $\mathrm{C}_{18} \mathrm{H}_{34} \mathrm{O}_{6}\left(\mathrm{CH}_{2} \mathrm{CH}_{2} \mathrm{O}\right)_{20}, \mathrm{C}_{22} \mathrm{H}_{43} \mathrm{O}_{6}\left(\mathrm{CH}_{2} \mathrm{CH}_{2} \mathrm{O}\right)_{20}, \mathrm{C}_{24} \mathrm{H}_{46} \mathrm{O}_{6}\left(\mathrm{CH}_{2} \mathrm{CH}_{2} \mathrm{O}\right)_{20}$, $\mathrm{C}_{24} \mathrm{H}_{44} \mathrm{O}_{6}\left(\mathrm{CH}_{2} \mathrm{CH}_{2} \mathrm{O}\right)_{20}$. Table 1shows the properties of the used nonionic surfactants. The surfactants purity 99.9\%. The physical and chemical 
properties of the used crude oil are listed in Table 2. The crude oil was obtained from Khalda Petroleum Company, western desert.

\section{Methods:}

\section{Measurement of surface tension, interfacial tension and Critical micelle concentration $(\mathrm{CMC})$ :}

Surface tension values of the used nonionic surfactants in their solutions were measured using Kruss tensiometer, GmbH, Germany, model K6 using Du-Nouy de-attached platinum ring method at $25{ }^{\circ} \mathrm{C}$. The platinum ring was washed using acetone and dried by flame after each measurement. A mean of three readings was considered at each surfactant concentration. The interfacial tension values of the surfactant solutions were measured between the surfactants solutions and the oil phase using the same procedures of the surface tension measurements. The platinum ring was mounted at the surfactant solution/oil interface and the reading was taken at the point where the ring is detached from the interface to the oil phase. The values of the surface tension were plotted against the concentration to obtain the surface tension-concentration profile of each nonionic surfactant. Critical micelle concentration (CMC) of each surfactant was determined by extrapolation method. Interfacial tension measurements were performed between crude oil and surfactant solutions $(0.1 \%$ wt $)$ at $25^{\circ} \mathrm{C}$.

\section{Experimental procedures of crude oil dispersion:}

The procedures of crude oil dispersion using the tested nonionic surfactants were performed as follows:

a. $250 \mathrm{~mL}$ of surfactant solutions with different concentration $(0.01-0.3 \mathrm{~g} / \mathrm{L})$ were used. 
b. The surfactants solutions were prepared in different salinity aqueous medium (0-80000 ppm).

c. The medium of the treatment was changed between alkaline to acidic $(\mathrm{pH}=5-8)$.

In the first of the experiments, a preliminary test was performed using the four nonionic surfactants (Tween-20,40,60 and 80) at concentration of $0.1 \mathrm{~g} / \mathrm{L}$ at $\mathrm{pH} 7$ to determine the best emulsification efficiency using these surfactants.

The surfactants solutions $(150 \mathrm{~mL})$ were poured on $(50 \mathrm{~mL})$ of the crude oil in the separating funnel and left for $6 \mathrm{~h}$ at $40{ }^{\circ} \mathrm{C}$ and then the funnel tap released. The obtained crude oil emulsions were placed in graduated measuring cylinders and left for complete separation of the oil and aqueous layer. The volume of the recovered crude oil was determined at the studied experiment conditions of: surfactant concentrations, salinity of the aqueous medium and $\mathrm{pH}$ of the medium. The emulsifying percent $(\mathrm{R} \%)$ was calculated based on the amount of the obtained crude oil at the end of each experiment using the following equation:

$\mathbf{R} \%=($ Volume of recovered crude oil $) / 200 \times 100$

\section{RESULTS AND DISCUSSION}

\section{Surface and interfacial properties of nonionic Tween surfactants}

Figure 1represents the surface tension-concentration profile of the nonionic surfactants under consideration at $25^{\circ} \mathrm{C}$ (Jiang et al., 2013 and $\mathrm{Ko}$ $\mathrm{KM}$ et al.,2014). It is clear that the gradual increase in the molecular weight 
of the different Tween surfactants increases the surface tension of their solutions (Zhang et al., 2006). Also, increasing the concentration of the surfactants in their aqueous medium gradually decreases their surface tension to reach to the stabilization at characteristic concentration. The interfacial tension (IFT) of the surfactant solution determines it ability to emulsify the organic phase in the aqueous phase and also determines the stability of the formed emulsions(Babadagli, 2005 andGong et al., 2005). Lower IFT valuesindicates the high tendency of the surfactant solution to emulsify the organic (oil) phase and also high stability of the formed emulsion, while moderate IFT values revealed the high emulsifying power of the surfactant solution accompanied by low emulsion stability formed. The Hydrophile Lipophile Balance (HLB) of surfactants determines the ability of surfactant molecules to dissolve in the oil phase. The lower the HLB value the more lipophilic or oil soluble the surfactant is, while the higher the HLB value the more water soluble or hydrophilic the surfactant is. The values of HLB of the studied surfactants are listed in Table 3. It is clear that all of the studied surfactants are oil soluble with different ratios. Tween-20 has HLB of 16.7 and Tween-80 has HLB of 14.3. This indicates the higher solubility of Tween-80 in the oil phase than Tweens-20,40,60.

The interfacial tension values of the studied nonionic surfactants were comparatively low, which showed their high tendency to emulsify crude oil with different stability degrees of the formed emulsions. IFT value of Tween80 was found at $3.2 \mathrm{mN} / \mathrm{m}$, which is slightly higher than the other nonionic surfactants under consideration. This revealed the slight stability of the formed oil/aqueous emulsions formed in the presence of Tween-80 surfactant. 
The HLB values of the studied nonionic surfactants were varied between 16.7 and 14.3, indicating their gradual change in their properties towards the interaction by the crude oil (organic phase)(Aktaset al., 2008), (Horozov, 2008).Tween- 80 has HLB value of 14.3 , which indicates its higher tendency to dissolve in the oil phase than Tweens-20,40,60. The review of the surface and interfacial properties of the different nonionic surfactants under investigation (Tween-20,40,60,80) indicates their high performance in emulsification and solubilization processes of crude oil, with high preferential for Tween-80 due to its high emulsification tendency. This encouraged the authors to direct towards application of Tween- 80 solution in emulsifying of crude oil from solid and aqueous phases (Binks and Tommy, 2005andZhanget al., 2008).

\section{Emulsification of crude oil using Tweens nonionic surfactants}

Screening of the studies nonionic surfactants during the emulsification of crude oil using $0.05,0.1,0.2,0.3 \mathrm{~g} / \mathrm{L}$ surfactants solutions at $\mathrm{pH} 7$ in pure water showed that their emulsifying efficiencies were increased by increasing the molecular weights of the surfactants, Figure 2. The efficiency was calculated based on the amount of the crude oil separated from the obtained crude oil/aqueous emulsion after settling at $25{ }^{\circ} \mathrm{C}$. This can be considered as a fair judgment on the efficiency of the studied surfactants, because this measurement considers the emulsifying of the crude oil and also the stability of the formed emulsion. Stable crude oil/aqueous solution emulsion is favored during the process. Tween-80 showed the highest emulsifying efficiency ranged between $60-77 \%$ at the different studied concentration ranges. 
Based on the screening test of the studied nonionic surfactants, Tween- 80 was extensively studied in emulsifying process of crude oil from solid and aqueous phases and determining the influence of the wide range surfactant concentration, salinity and $\mathrm{pH}$ of the medium.

\section{Effective parameters on the emulsification process}

In this section, the influence of the different parameters on the emulsifying process of crude oil including the surfactant concentration in the range of $0.02-0.3 \mathrm{~g} / \mathrm{L}, \mathrm{pH}$ of the medium in the range of 5-9, and salinity at $0-$ 80000 ppm were studied.

\section{Effect of surfactant concentration}

Table 4 represents the emulsifying efficiency in the presence of different concentrations of Tween-80 nonionic surfactant in the neutral medium $(\mathrm{pH}=7)$. It is clear that the emulsifying efficiency is increased by increasing the surfactant concentration to reach to the maximum value at $77 \%$. Further increase has negativeeffect on its efficiency. This can be attributed to the surface activity of Tween-80 in the solution. Also, increasing the concentration considerably decreases the surface tension of the solution and increases the interaction between the surfactant solution and the oil(Beraet al., 2015 and Beraet al., 2012a). The optimum amount of emulsified crude oil was obtained in the presence of $0.3 \mathrm{~g} / \mathrm{L}$ of Tween- 80 solution.

\section{Effect of salinity}

The salinity of the nonionic surfactant solution has a great influence on its surface activity. Figure 3 represents the influence of the salinity on the surface tension-concentration profile of Tween-80 nonionic surfactant at 25 ${ }^{\circ} \mathrm{C}$. It is clear that increasing the salinity of the medium increases the surface 
tension values considerably to reach to its maximum value at $80000 \mathrm{ppm}$. Increasing the surface tension values of Tween-80 solution at constant surfactant concentration by increasing the salinity indicates the decrease in the surface activity. Increasing the salinity of the medium leads to salt-out of the nonionic surfactants from the solution. This leads to decrease the amount of dissolved Tween- 80 molecules in the medium, which raises the surface tension and lowers the surface activity.

The effect of salinity on the emulsifying efficiency is represented byFigure 4. It is clear from Figure 4 that the maximum efficiency was obtained at $77 \%$ and $55.2 \% \mathrm{~g} / \mathrm{L}$ surfactant concentration at salinity of 0.0 ppm. The increase in the salinity of the medium decreased the emulsification efficiency considerably to reach to the lowest values at $60 \%$ and $46.8 \%$ in the presence of 0.02 and $0.3 \mathrm{~g} / \mathrm{L}$ surfactant concentration at salinity of 80000 ppm. The decrease in efficiency by increasing the salinity of the surfactant solution is attributed to the decrease of the effective amount of Tween-80 dissolved in the solution which decreases the amount of the emulsified oil and also to the decrease in the surface activity of the solution.

\section{Effect of pH}

Figure 5 represents the variation of the emulsifying efficiency at different $\mathrm{pH}$ values of the solutions. It is clear that the maximum process efficiency was obtained at neutral medium of $\mathrm{pH} 7$. It is obvious from Figure 5 that the acidic and alkaline media have negative impact on the emulsifying efficiency of the crude oil in the aqueous medium of the crude oil in the aqueous medium. Furthermore, comparing the process efficiencies at acidic and 
alkaline media revealed that the emulsification efficiency in the alkaline medium is higher than that of the acidic medium(Lunkenheimer and Malysa, 2003;Carey and Stubenrauch, 2009). This may be attributed to the relation between the surface activity and the $\mathrm{pH}$ of the medium.

Figure 6 represents the relation between the surface tension of Tween-80 surfactant solution at different concentrations and the $\mathrm{pH}$ of the medium.

It is clear from Figure 6 that the surface tension values of Tween-80 in alkaline medium are comparatively lower than those in the acid media,which may be attributed to the interaction between the polyethylene glycol chains and the hydroxide ions and also by the hydronium ions. Hydronium ions $\left(\mathrm{H}_{3} \mathrm{O}^{+}\right)$are attracted to the lone pairs of the oxygen atoms in the polyethylene glycol chains, which decreases the hydrogen bonds between the nonionic surfactant and the water molecules. This decreases their solubility in the aqueous medium, which decreases the surface activity of their solutions. Consequently, their interfacial is decreased. The decrease in the interfacial activity decreases the emulsifying efficiency as the interaction between the crude oil and aqueous medium is decreased(Kroschwitz, 1994).

In alkaline medium, the interaction between the Tween- 80 molecules and the hydroxide ions $\left(\mathrm{OH}^{-}\right)$is repulsive, which increases the interaction between the surfactant and water molecules. That increases the surface activity of the surfactant solution. This can be observed from the lower surface tension values of Tween-80 solution at various concentrations in alkaline medium, (Figure 6). Increasing the surface activity of Tween-80 solution in alkaline medium increases its interfacial activity (Kaptay, 2004) and (Sethumadhavanet al., 2001) which increases its emulsifying efficiency. 
The emulsification efficiency was calculated based on the amount of separated crude oil from the cut-of emulsion after $3 \mathrm{~h}$. The higher surface activity of Tween-80 solution is considered as a disadvantage of the emulsification process. That is due to the obtained cut-off emulsion is comparatively stable.

In neutral medium, the emulsifying efficiencies were at the maximum value, which can be attributed to the balance between the interaction and repulsion occurring between the surfactant and water molecules. This effect was studied at a wide range of salinity and the results revealed the same behavior at the salinity range.

\section{CONCLUSIONS}

The remediation of spilled crude oil in the environment can be performed using the nonionic surfactants. The process of the remediation can be performed by dispersing the crude oil in the aqueous medium to decrease its impact on the aquatic system. The nonionic Tween surfactants exhibit high efficiencies in dispersing the crude oil in the water medium. The dispersing efficiency increased by increasing the amount of the nonionic surfactants.

\section{REFERECNES}

Aktas, Z.; Cilliers, J. and Banford, A.(2008): "Dynamic froth stability: particle size, airflow rate and conditioning time effects". Int J Miner Process. 87(1-2):65-71.

Ata, S. (2008): "Coalescence of bubbles covered by particles". Langmuir. 24(12):6085-91. doi:10.1021/la800466x. 
Aveyard, R.; Binks, B.P. and Fletcher PDI (1994a): "Aspects of aqueous foam stability in the presence of hydrocarbon oils and solid particles". Adv. Colloid Interface Sci. 48:93-120.

Aveyard,R.; Binks, B. P.and Fletcher PDI(1994b): "Contact angles in relation to the effects of solids on film and foam stability". J Dispers Sci Technol. 15(3):251-71. doi:10.1080/01932699408943557.

Babadagli, T. (2005): "Analysis of oil recovery by spontaneous imbibitions of surfactant solution". Oil Gas Sci Technol Rev 60: 697-710.

Babadagli, T.; Boluk, Y. (2005): "Oil recovery performances of surfactant solutions by capillary imbibitions". J Colloids Interface Sci. 282(1):162-75.

Bera, A.; Kissmathulla, S. and Ojha, K. (2012): " Mechanistic study of wettability alteration of quartz surface induced by nonionic surfactants and interaction between crude oil and quartz in presence of sodium chloride salt". Energy Fuels. 26(6): 3634-43.

Bera, A.; Kumar, S. and Mandal, A. (2012):"Temperature-dependent phase behavior, particle size, and conductivity of middle-phase microemulsions stabilized by ethoxylated nonionic surfactants". J Chem Eng Data. 57(12):3617-23.

Bera, A.; Ojha, K. and Mandal, A. (2013): "Synergistic effect of mixed surfactant systems on foam behavior and surface tension ". J Surfactants Deterg. 16(4):621-30.

Bera, A.; Mandal, A. and Kumar, T. (2015): " Effect of rock-crude oil-fluid interactions on wettability alteration of oil-wet sandstone in presence of surfactants ". Pet Sci Technol. 33(5):542-9.

Binks, B. P.; Tommy,S. H. (2005): "Aqueous foams stabilised solely by silica nanoparticles ". Angew Chem. Int. Engl.Ed. 44(24):3722-5.

Carey,E.; Stubenrauch, C. (2009): "Properties of aqueous foams stabilized by dodecyltrimethylammonium bromide ". J Colloid Interface Sci. 333(2):619-27.

Dippenaar, A. (1982a): "The destabilization of froth by solids " I. The mechanism of film rupture. Int. J. Miner Process. 9(1):1-14. 
Dippenaar, A. (1982b): "The destabilization of froth by solids. II. The ratedetermining step ". Int. J Miner Process. 9(1):15-22.

Du, Z.; Bilbao-Montoy,M. P.and Binks, B. P.: " Outstanding stability of particle-stabilized bubbles ". Langmuir. 19(8):3106-8.

El-Batanoney, M.; Abdel-Monghny, T. and Ramazi, M. (1999): "The effect of mixed surfactants on enhancing oil recovery".J Surfactants Deter. 2(2):201-5.

Exerowa, D.R.; Kruglyakov, P.M. (1998): "Foams and foam films". Amsterdam: Elsevier.

Frye,G. and Berg, J.C. (1989): " Antifoam action by solid particles". J Colloid Interface Sci. 127(1):222-38. doi:10.1016/0021-9797(89).

Gong, Y.;Li, Z. and An, J. (2005): "The properties of sodium naphthalene sulfonate in lowering interfacial tension and its possibility of application in EOR ". J Dispersion Sci Technol. 26(4):503-7.

Gonzenbach,U. T.;Studart,A. R. and Tervoort, E.(2006): "Ultrastable particlestabilized foams". Angew Chem Int Ed. 45(21):3526-30.

Hoff,E.; Nystrom, B. and Lindman, B. (2001):"Polymer-surfactant interactions in dilute mixtures of a nonionic cellulose derivative and an anionic surfactant". Langmuir. 17(1):28-34.

Horozov,T. S. (2008): " Foams and foam films stabilized by solid particles". Curr Opin Colloid Interface Sci. 13(3):134-40.

Huang, D.; Nimolvo, A. and Wasan D. (1986): "Foams: basic properties with applications to porous media. Langmuir". 2(5):672-7.

Jiang, P.; Li, N. and Ge, J. (2013):"Efficiency of a sulfobetaine-type surfactant on lowering IFT at crude oil-formation water interface". Colloids Surf A. 443:141-8.

Judson, R. S.;Martin, M. T. and Reif,D. M.(2010): “Analysis of oil spill dispersants using rapid, in vitro tests for endocrine and other biological activity". Environ. Sci. Technol. 44:5979-5985.

Kaptay, G. (2004): "Interfacial criteria for stabilization of liquid foams by solid particles ". Colloids Surf A. 230(1-3):67-80. 
Ko, K. M.; Chon,B. H. and Jang, S. B. (2014):"Surfactant flooding characteristics of dodecyl alkyl sulfate for enhanced oil recovery". J Ind Eng Chem. 20(1):228-33.

Kroschwitz,J.I. (1994): Kirk-Othmer encyclopedia of chemical technology. 4th ed. New York: Wiley.

Lunkenheimer, K.and Malysa, K. (2003): "A simple automated method of quantitative characterization of foam behavior". Polymer Int. 52(4):536-54.

Major, D. N. and Wang, H. (2012): "How public health impact is addressed: a retrospective view on three different oil spills". Toxicological and Environmental Chemistry 94:442-467.

Mascarelli, A. (2010): “Deepwater Horizon: after the oil”. Nature467:22-24.

Paine, R.T.and Ruesink,J.L. (1996): “Trouble on oiled waters: lessons from the Exxon Valdez oil spill". Annual Review of Ecology and Systematics 27:197-235.

Peterson, C. H. andRice, S. D.(2003):"Long-term ecosystemresponse to the Exxon Valdez oil spill”. Science 302(5653):2082-2086. Research 47:473-489.

Sadoc, J.F.;Rivier,N. and editors. (1999): "Foams and emulsions “. NATO ASI series E, vol. 354. Dordrecht: Kluwer.

Sethumadhavan,G. N.; Nikolov,A.D. and Wasan,D.T. (2001): "Stability of liquid films containing monodisperse colloidal particles". J Colloid Interface Sci. 240(1):105-12.

Shirtcliffe,N. J.; McHale, G.andNewton M. (2003): " Intrinsically super hydrophobic organosilica sol-gel foams. Langmuir" .19(13): 5626-31.

Sriram,K.; Lin, G. X.and Jefferson,A.M.(2011): "Neurotoxicity following acute inhalation exposure to the oil dispersant COREXIT EC9500A”. J.Toxic.\& Enviro.Health A 74(21):1405-1418.

Stephane; Stone,J. and Demes, K. (2014): "Consequences of oil spills: a review and framework for informing planning)". Ecology and society 19(2):26. 
Vosyliene, M. Z. and Kazlauskiene, N. (2005): "Toxic effects of crude oil combined with oil cleaner simple green on yolk-sac larvae and adult rainbow trout Oncorhynchus mykiss". Envirom. Sci.Pollut. Res.12(3):136-139.

Wolfe, M. F. andOlsen, H. E. (1999): "Induction of heat shock protein (hsp)60 in Isochrysis galbana exposed to sublethal preparations of dispersant and Prudhoe Bay crude oil". Marine Environmental research 47:473-489.

Wu, Y.; Shuler,P. J. and Blanco, M. (2006):“An experimental study of wetting behavior and surfactant EOR in carbonates with model components". In: SPE/DOE improved oil recovery, April 22-26, Tulsa, Oklahoma.

Zhang, D. L.; Shunhua, L. and Puerto, M. (2006):"Wettability alteration and spontaneous imbibitions in oil-wet carbonate formations". J Pet Sci Eng. 52(1-4):213-26.

Zhang S.; Sun, D. and Dong, X. (2008): "Aqueous foams stabilized with particles and nonionic surfactants ". Colloids Surf A. 324(1-3):18.

Zochhi G.; Broze, G. and editors. (1999): " Handbook of detergents, part A: properties". Surfactant science series. vol. 59, PP148-162 Marcel Dekke 


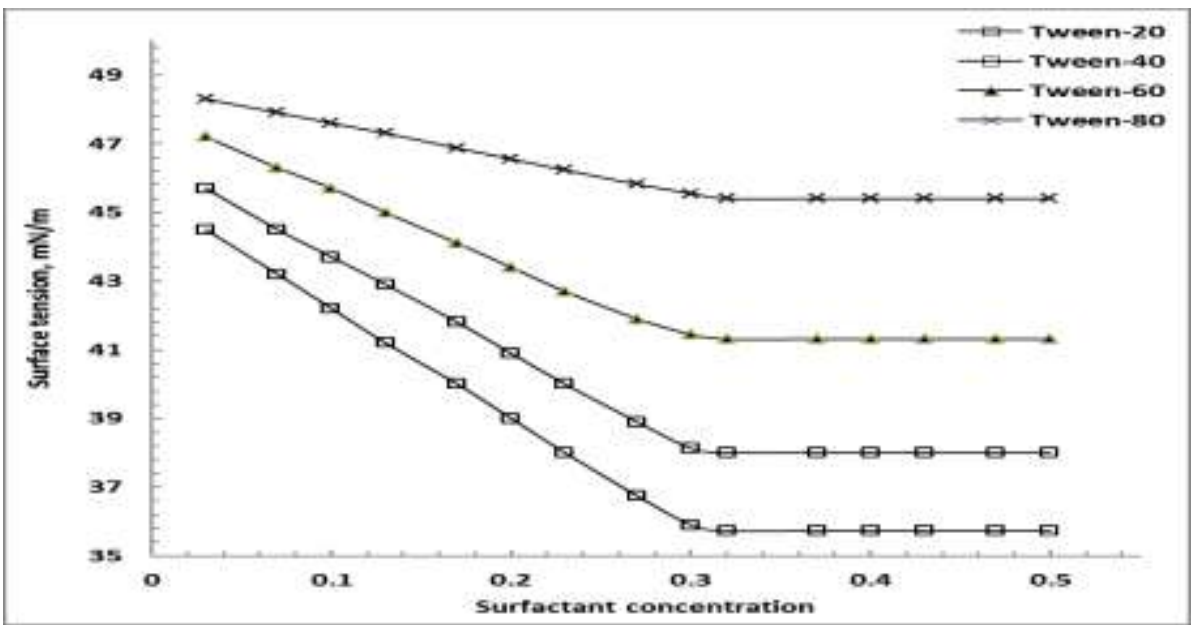

Figure 1: Surface tension-concentration profile of the studied surfactants at 25 ${ }^{\circ} \mathrm{C}$.

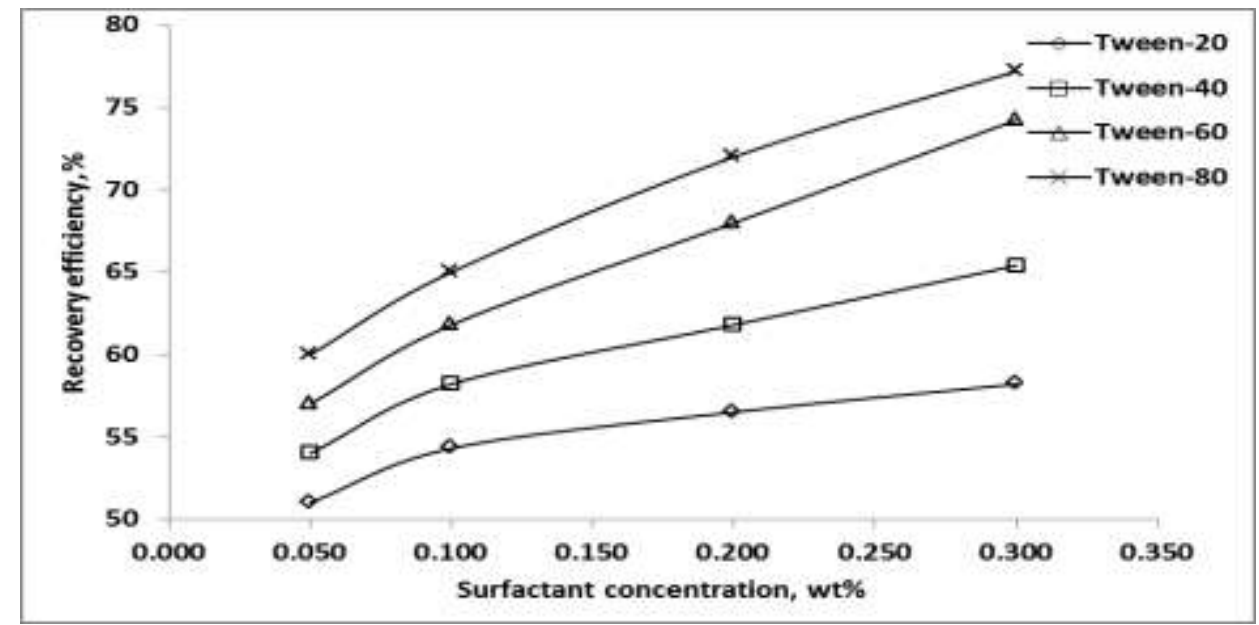

Figure 2: Effect of Tween type on emulsificationefficiency of crude oil. 
J. Environ. Sci.

Institute of Environmental Studies and Research - Ain Shams University

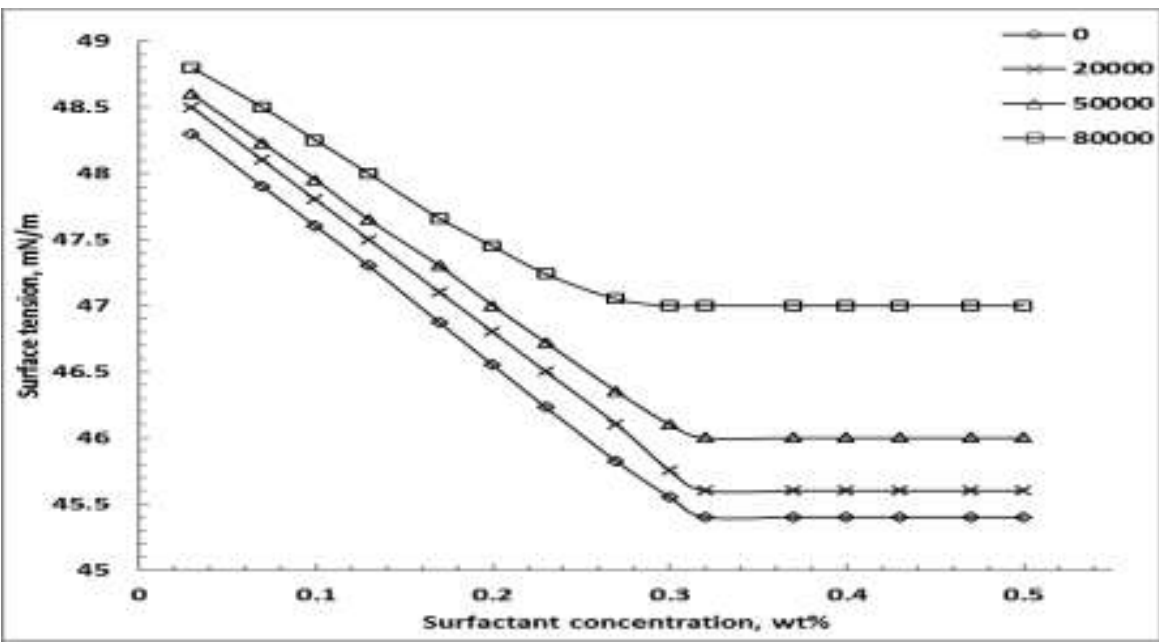

Figure 3: Effect of salinity on surface tension-concentration profile of Tween-80 at $25^{\circ} \mathrm{C}$.

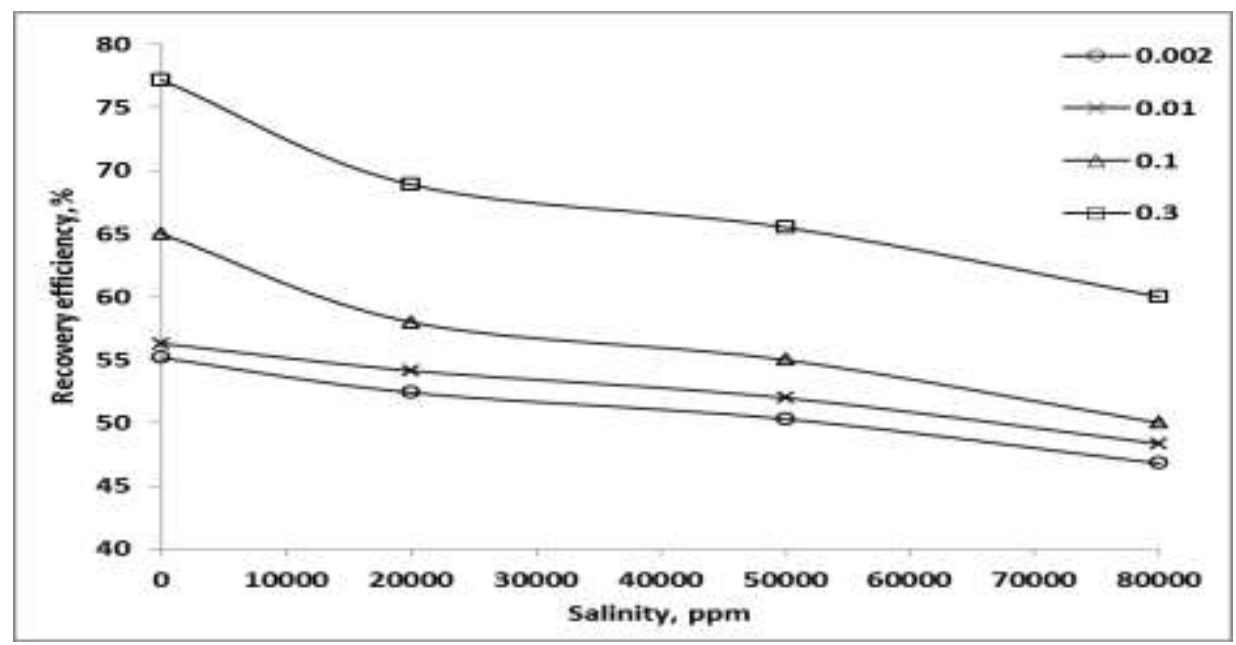

Figure 4: Effect of salinity of the medium on the emulsifying process efficiency at different Tween-80 concentrations. 


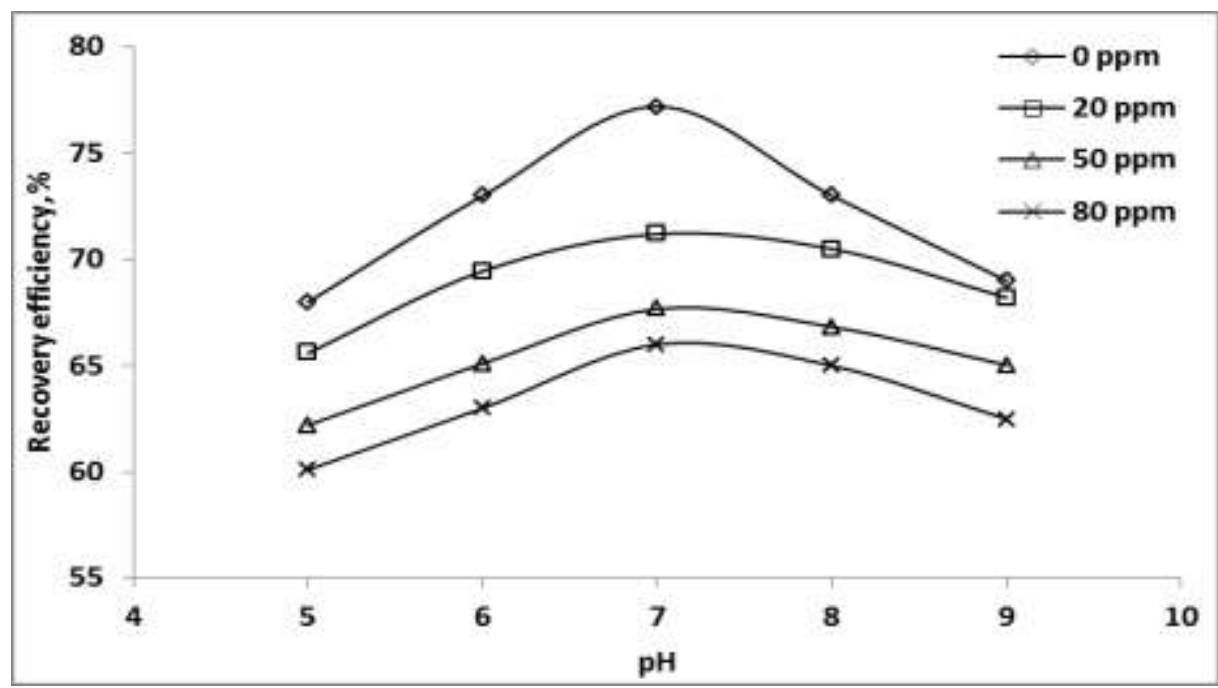

Figure 4: Effect of $\mathrm{pH}$ of the medium on the emulsifyingprocess efficiency using Tween-80 solution.

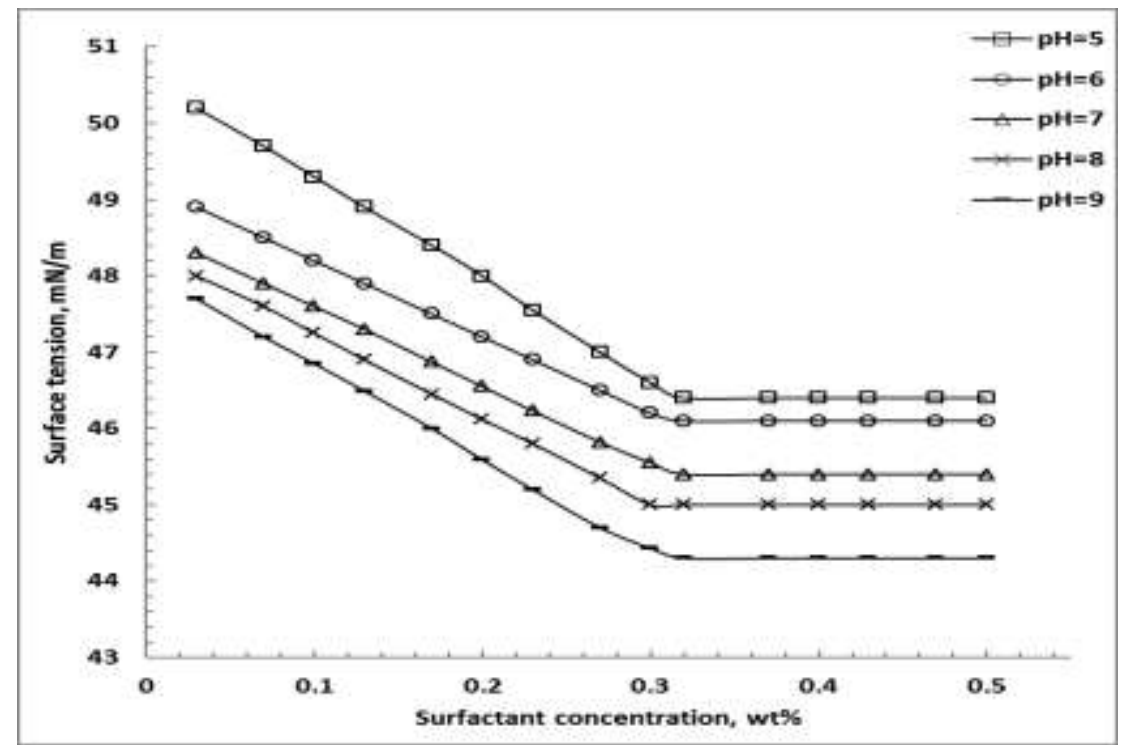

Figure 6: variation of surface tension-concentration of Tween-80 at different $\mathrm{pH}$ of the medium at $25 \mathrm{oC}$. 
J. Environ. Sci.

Institute of Environmental Studies and Research - Ain Shams University

Table 1: Properties of the used surfactants

\begin{tabular}{|c|c|c|c|}
\hline Surfactant name & Formula & Molecular weight, g/mole & HLB \\
\hline \hline Tween-20 & $\mathrm{C}_{18} \mathrm{H}_{34} \mathrm{O}_{6}\left(\mathrm{CH}_{2} \mathrm{CH}_{2} \mathrm{O}\right)_{20}$ & 1227.5 & 16.7 \\
\hline Tween-40 & $\mathrm{C}_{22} \mathrm{H}_{43} \mathrm{O}_{6}\left(\mathrm{CH}_{2} \mathrm{CH}_{2} \mathrm{O}\right)_{20}$ & 1282.6 & 15.6 \\
\hline Tween-60 & $\mathrm{C}_{24} \mathrm{H}_{46} \mathrm{O}_{6}\left(\mathrm{CH}_{2} \mathrm{CH}_{2} \mathrm{O}\right)_{20}$ & 1311.7 & 14.9 \\
\hline Tween-80 & $\mathrm{C}_{24} \mathrm{H}_{44} \mathrm{O}_{6}\left(\mathrm{CH}_{2} \mathrm{CH}_{2} \mathrm{O}\right)_{20}$ & 1310.6 & 14.3 \\
\hline
\end{tabular}

Table 2: Physical properties of the crude oil used

\begin{tabular}{|c|c|}
\hline Oil properties & Value \\
\hline Average molecular weight (g/mol) & 187.9 \\
\hline Density at $60{ }^{\circ} \mathrm{F}(\mathrm{g} / \mathrm{cc})$ & 0.8419 \\
\hline API gravity @ 60'F & 36.40 \\
\hline Pour point, ${ }^{\circ} \mathrm{C}$ & 36.34 \\
\hline Wax content, wt. $\%$ & 12.9 \\
\hline Water content, ppm & 60.8 \\
\hline Sulfur content, wt $\%$ & 0.19 \\
\hline Flash point, ${ }^{\circ} \mathrm{C}$ & 3 \\
\hline Total Acid Number, mg KOH/gm. & 0.4435 \\
\hline
\end{tabular}

Table 3: Surface and interfacial properties of the studied nonionic surfactants at $25 \mathrm{oC}$

\begin{tabular}{|c|c|c|c|}
\hline Tween & CMC & IFT & HLB \\
\hline \hline 20 & 0.0499 & 2.5 & 16.7 \\
40 & 0.0333 & 2.8 & 15.6 \\
60 & 0.0167 & 3.0 & 15.0 \\
80 & 0.0125 & 3.2 & 14.3 \\
\hline
\end{tabular}

Table 4: Effect of Tween-80 concentration on the emulsifying process of crude oil

\begin{tabular}{|c|c|}
\hline Surfactant concentration, g/L & Emulsification efficiency \% \\
\hline 0.002 & 55 \\
0.01 & 56 \\
0.05 & 60 \\
0.1 & 65 \\
0.2 & 72 \\
0.3 & 77 \\
\hline
\end{tabular}




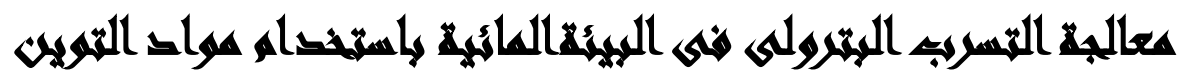

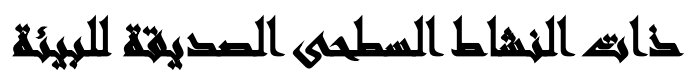

[1]

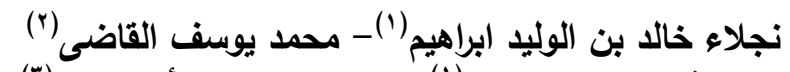

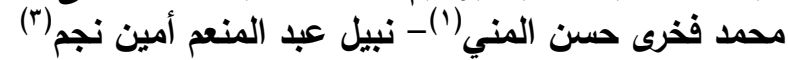

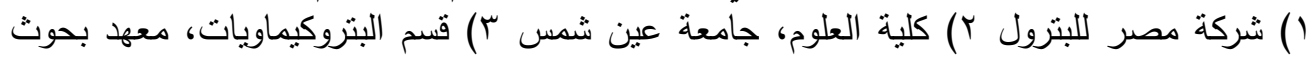
البترول

\section{المستخلس}

يعتبر تنرب النفط الخام فى البيئة سواء فى التربة أو مياه الأنهار والبحار كارثة بيئية كبيرة،

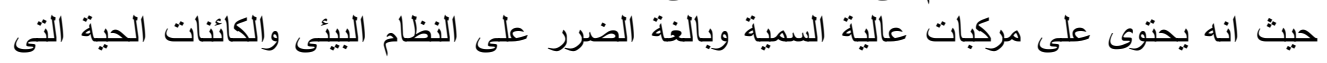

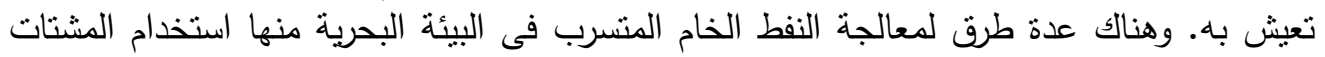

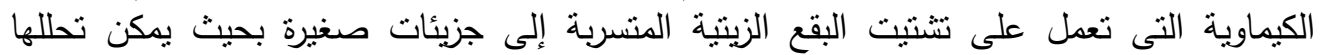

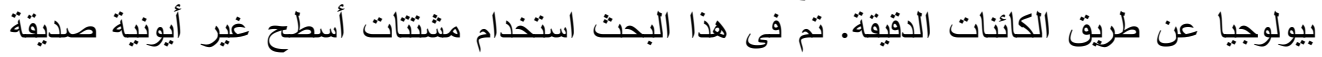

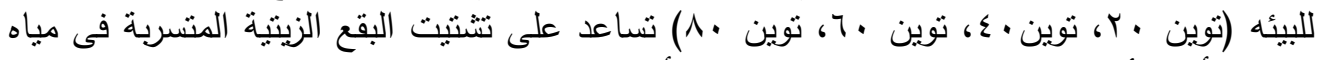

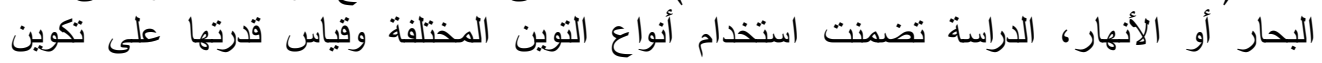
المستحلب. كما نم دراسة العلاقة بين النشاط السطحى لأنواع التوين المختلفة وقدرتها على تشنتيت ألنى

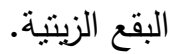
الكلمات الدالة: النفط الخام، كارثة بيئية، المشتتات الكيميائية، المستحلب، التوين. 